\title{
KEBUTUHAN RUANG PARKIR EFEKTIF PADA PASAR BAROS
}

\author{
Abdul Latief Noor Ikhsan', Telly Rosdiyani², dan Nila Prasetyo Artiwi³ \\ 1,2,3 Program Studi Teknik Sipil, Universitas Banten Jaya, Jl. Raya Ciwaru II No.73Kota Serang, Banten. \\ Email: axselabdullatief@gmail.com \\ Email: tellyrosdiyani004@gmail.com \\ Email: prasetyonila2@gmail.com
}

\begin{abstract}
ABSTRAK
Pasar Baros merupakan pasar tradisional di Kabupaten Serang yang terletak di Kecamatan Baros, memiliki luas $\pm 4350 \mathrm{~m}^{2}$. Area parkir Pasar Baros belum tersusun dengan rapih dan tidak memenuhi kebutuhan, untuk memenuhi kebutuhan parkir penulis mencoba untuk menganalisa berapa kebutuhan ruang parkir dan bagaimana desain ruang parkir yang efektif. Pengambilan data dilakukan dengan survei pencatatan plat nomor kendaraan sepeda motor dan mobil yang masuk dan keluar beserta lamanya parkir untuk kemudian dilakukan analisa data yang mengacu pada Pedoman Teknis Penyelenggaraan Fasilitas Parkir, Direktorat Jenderal Perhubungan Darat 1996. Dari hasil analisa diperoleh nilai Akumulasi parkir tertinggi terjadi pada hari Senin (95 kend/15 menit untuk sepeda motor) dan (29 kend/15 menit untuk mobil). Volume parkir sepeda motor maksimum terjadi dihari Senin (624 kendaraan), sedangkan mobil (87 kendaraan). Durasi rata-rata parkir terlama (2 jam 47 menit) terjadi pada kendaraan mobil. Dari nilai Indeks parkir sepeda motor yang terjadi berkisar antara 63,69\%-123,44\% dan mobil sebesar 133,83\%$200,83 \%$, angka tersebut melebihi $100 \%$ sehingga ruang parkir yang ada dinyatakan sudah tidak mampu menampung kendaraan. Dengan mengacu pada Pedoman Teknis Penyelenggaraan Fasilitas Parkir dan keadaan faktual di lapangan disimpulkan bahwa rekomendasi untuk penambahan ruang parkir sepeda motor dengan luasan $257,4 \mathrm{~m}^{2}$, perencanaan ruang parkir mobil dengan luas $1102,5 \mathrm{~m}^{2}$ dan pemindahan tempat penampungan sampah ke area belakang pasar.
\end{abstract}

Kata kunci: Karakteristik, Kebutuhan ruang parkir, Kendaraan, Parkir.

\begin{abstract}
Baros Market is a traditional market in Serang Regency, located in Baros District, with an area of $\pm 4350 \mathrm{~m}^{2}$. The parking area at Pasar Baros is not neatly arranged and does not meet the needs. To meet the parking needs, the writer tries to analyze how much parking space is needed and how to design an effective parking space. Data collection was carried out by surveying the recording of incoming and outgoing motorbikes and cars along with the length of parking for later data analysis which refers to the Technical Guidelines for the Implementation of Parking Facilities, Directorate General of Land Transportation 1996. From the analysis results obtained the highest parking accumulation value occurred on Monday. (95 vehicles / 15 minutes for motorbikes) and (29 vehicles / 15 minutes for cars). The maximum parking volume for motorbikes occurs on Monday (624 vehicles), while for cars (87 vehicles). The longest average parking duration (2 hours 47 minutes) occurred for cars. From the value of the motorcycle parking index that occurred ranged from $63.69 \%-123.44 \%$ and cars from $133.83 \%-200.83 \%$, this figure exceeds $100 \%$ so that the existing parking spaces are declared unable to accommodate vehicles. Referring to the Technical Guidelines for the Implementation of Parking Facilities and the factual conditions in the field, it is concluded that the recommendation is to increase the parking space for motorbikes with an area of $257.4 \mathrm{~m}^{2}$, planning a car park space with an area of $1102.5 \mathrm{~m}^{2}$ and moving the garbage collection to the rear market area.
\end{abstract}

Keywords: Characteristics, Parking, Parking space requirements, Vehicles. 


\section{PENDAHULUAN}

Masalah kebutuhan fasilitas parkir adalah hal yang biasa terjadi seiring terus bertambahnya tingkat kepemilikan kendaraan. Hal tersebut menyebabkan kebutuhan akan fasilitas parkir menjadi sangat penting bila dikaitkan bahwa parkir merupakan bagian yang tak dapat dipisahkan dari sistem transportasi. Apabila sistem perparkiran tidak diperhatikan maka masalah yang akan timbul yaitu kemacetan, penurunan aksesibilitas suatu kawasan dan lain-lain. Pasar Baros, merupakan sebuah pasar tradisional di Kabupaten Serang yang terletak di Kecamatan Baros, merupakan salah satu pasar yang ber tipe $C$ dan memiliki luas \pm 5000 meter. Letak Pasar Baros yang sangat strategis dimana pada jalur lintas antar kota Pandeglang dengan kota Serang. Kondisi eksisting saat ini belum memiliki area parkir yang layak yang dapat menampung kendaraan pengunjung pasar, padahal banyak pengunjung pasar mulai dari Baros, Petir, Pandeglang, dll sehingga sepeda motor maupun mobil milik pengunjung hanya parkir pada badan jalan. Area parkir pasar Baros belum tersusun dengan layak, sebagaimana lahan parkir pasar pada umumnya, hal ini berpengaruh terhadap kenyamanan, keamanan pengunjung Pasar Baros tersebut. Tingginya jumlah pengunjung pasar, bisa diasumsikan dengan melihat dari banyaknya kendaraan yang parkir di dalam pasar maupun disekitar pasar.

Akibat dari kapasitas parkir yang tidak mencukupi sejumlah kendaraan hanya parkir pada bahu jalan (on street). Berdasarkan latar belakang masalah maka permasalahan yang akan diteliti adalah bagaimanakah kondisi existing ruang parkir Pasar Baros, berapa kebutuhan ruang parkir pada Pasar Baros untuk memenuhi pengguna parkir yang ada dan bagaimana rekomendasi ruang parkir yang efektif di Pasar Baros agar memenuhi pengguna parkir yang ada. Berdasarkan rumusan masalah yang sudah dijelaskan diatas maka tujuan penelitian ini untuk mengetahui kondisi existing ruang parkir Pasar Baros, mengetahui kebutuhan ruang parkir efektif pada kawasan Pasar Baros dan memberikan gambaran perencanaan tentang kebutuhan lahan parkir efektif dengan memanfaatkan lahan parkir yang tersedia. Dengan mengacu pada Pedoman Teknis Penyelenggaraan Fasilitas Parkir Direktorat Jenderal Perhubungan Darat 1996 dan beberapa referensi jurnal yang relevan dan serupa seperti dari jurnal Telly Rosdiyani tentang Kajian Kebutuhan Ruang Parkir Sebagai Pengendali Lalu Lintas di Kampus Universitas Muhammadiyah (2016) dan jurnal Fauziah Syarifuddin tentang Kebutuhan Ruang Parkir Pada Rumah Sakit Bhayangkara Di Kota Makassar (2017), keduanya memiliki kesamaan tujuan yaitu untuk mengetahui kebutuhan parkir kendaraan yang ada.

\section{METODOLOGI PENELITIAN}

Penelitian ini dilakukan di Pasar Baros, Kecamatan Baros khususnya pada ruang parkirnya. Pertimbangan pemilihan lokasi ini dikarenakan Pasar Baros yang strategis dan terletak di pinggir jalan raya, selain itu Pasar Baros ini merupakan salah satu pasar yang padat pengunjung dengan ruang parkir yang minim. Waktu penelitian merupakan batasan waktu yang digunakan dalam melakukan penelitian. Adapun waktu penelitian ini yaitu:

a. Hari Senin, mulai pukul 06:00 pagi sampai dengan pukul 06:00 sore. Hari Senin dimaksudkan untuk mewakili hari awal dari setiap per 1 minggu dan mewakili hari normal (weekday).

b. Hari Minggu, mulai pukul 06:00 pagi sampai dengan pukul 06:00 sore. Hari Minggu untuk mewakili hari libur (weekend).

Pengumpulan data primer merupakan hasil survei lapangan yang dilakukan oleh surveyor dengan cara mencatat nomor plat kendaraan, waktu masuk kendaraan dan waktu keluar kendaraan dalam satu hari. Data sekunder diperoleh dari dari mengutip data informasi yang sudah ada bekerjasama dengan instansi pengelola atau sumber-sumber yang dianggap berkepentingan untuk dijadikan bahan masukan dan referensi. Data sekunder yang dibutuhkan antara lain site plan atau denah keseluruhan Pasar Baros, luas bangunan keseluruhan Pasar Baros, luas area parkir existing di Pasar Baros dan jumlah toko/lapak-lapak perdagangan di Pasar Baros. Pengolahan data dilakukan dengan cara mengumpulkan, mengidentifikasi, serta mengolah data tertulis yang diperoleh, dalam hal ini memerlukan beberapa peraturan sebagai studi pustaka yang diperlukan sebagai bahan referensi dan tambahan pengetahuan. Observasi lapangan dilakukan dengan tujuan untuk mengadakan pengamatan di lokasi parkir khususnya di area parkir Pasar Baros. Pengamatan yang dilakukan meliputi jumlah dan waktu kendaraan yang masuk ke tempat parkir dan keluar dari tempat parkir, jumlah Satuan Ruang Parkir (SRP) pada area parkir existing Pasar Baros dan pengukuran area parkir existing Pasar Baros. 


\section{DATA DAN ANALISA}

Data-data hasil pengamatan di lokasi penelitian, selanjutnya diolah dan di analisis sesuai rumusan masalah dalam penelitian. Luas area parkir di Pasar Baros kurang lebih $540 \mathrm{~m} 2$. Saat ini hanya terdapat 97 jumlah petak parkir sepeda motor, lahan parkir di Pasar Baros 60\% nya terpaksa digunakan oleh pedagang kaki lima. Yang dimaksud dengan karakteristik parkir diantaranya: Akumulasi parkir, Volume parkir, Durasi parkir, Kapasitas parkir, Indeks parkir dan Tingkat pergantian parkir (turnover).

\subsection{Akumulasi Parkir}

Tabel 1 menjelaskan akumulasi sepeda motor pada hari Minggu dan hari Senin, akumulasi maksimum pada hari Minggu berada pukul 07:00-08:00 dengan jumlah 75 kendaraan. Sedangkan hari Senin akumulasi maksimum dengan jumlah 83 kendaraan yaitu pada pukul 08:00-09:00. Pada hari Senin nilai akumulasi parkir lebih besar, artinya hari Senin lebih ramai pengujung yang akan berbelanja di pasar.

Tabel 1. Rekapitulasi Akumulasi Parkir Sepeda Motor

\begin{tabular}{|c|c|c|c|c|}
\hline \multicolumn{5}{|c|}{ Hari Minggu } \\
\hline \multirow{2}{*}{ Interval } & \multicolumn{2}{|c|}{$\begin{array}{c}\text { Jumlah } \\
\text { Kendaraan }\end{array}$} & \multirow{2}{*}{ Akumulasi } & \multirow{2}{*}{$\begin{array}{c}\text { Kend.yang } \\
\text { sudah ada } \\
31\end{array}$} \\
\hline & Masuk & Keluar & & \\
\hline $06: 00-07: 00$ & 48 & 27 & 52 & \\
\hline 07:00 - 08:00 & 74 & 51 & 75 & \\
\hline 08:00 - 09:00 & 71 & 76 & 70 & \\
\hline 09:00 - 10:00 & 68 & 69 & 69 & \\
\hline $10: 00-11: 00$ & 63 & 72 & 60 & \\
\hline $11: 00-12: 00$ & 41 & 33 & 68 & \\
\hline $12: 00-13: 00$ & 31 & 45 & 54 & \\
\hline $13: 00-14: 00$ & 43 & 50 & 47 & \\
\hline $14: 00-15: 00$ & 31 & 33 & 45 & \\
\hline $15: 00-16: 00$ & 25 & 26 & 44 & \\
\hline $16: 00-17: 00$ & 10 & 17 & 37 & \\
\hline $17: 00-18: 00$ & 8 & 8 & 37 & \\
\hline Jumlah & 513 & 507 & 658 & \\
\hline
\end{tabular}

\begin{tabular}{ccccc}
\hline Hari Senin & \multicolumn{5}{c}{} & \multicolumn{1}{c}{ Kend.yang } \\
Interval & \multicolumn{2}{c}{ Jumlah } & & Kendaraan \\
& Masuk & Keluar & Akumulasi & sudah ada \\
\hline 06:00 - 07:00 & $\mathbf{9 7}$ & 58 & 62 & \\
07:00 - 08:00 & 62 & 61 & 63 & \\
08:00 - 09:00 & 85 & 65 & $\mathbf{8 3}$ & \\
09:00 - 10:00 & 78 & 86 & 75 & \\
10:00 - 11:00 & 69 & 78 & 66 & \\
11:00 - 12:00 & 57 & $\mathbf{9 1}$ & 32 & \\
12:00 - 13:00 & 32 & 16 & 48 & \\
13:00 - 14:00 & 45 & 53 & 40 & \\
14:00 - 15:00 & 32 & 29 & 43 & \\
15:00 - 16:00 & 27 & 39 & 31 & \\
16:00 - 17:00 & 11 & 38 & 4 & \\
17:00 - 18:00 & 6 & 8 & 2 & \\
Jumlah & $\mathbf{6 0 1}$ & $\mathbf{6 2 2}$ & $\mathbf{5 4 9}$ & \\
\hline
\end{tabular}
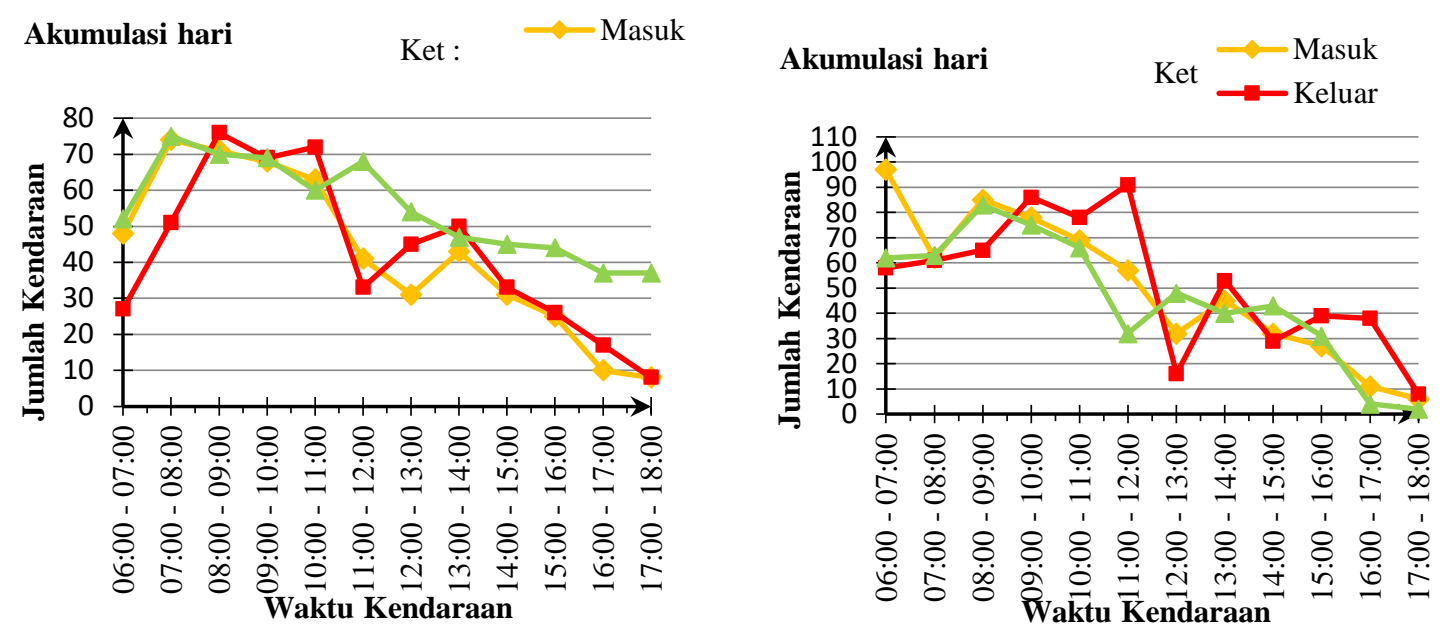

Sedangkan Tabel 2 memperlihatkan akumulasi untuk mobil pada hari Minggu dan hari Senin, akumulasi maksimum yang terjadi pada hari Minggu dengan jumlah 16 kendaraan pada pukul 10:00-11:00 dan pukul 11:00-12:00. Hari Senin terjadi akumulasi parkir maksimum pada pukul 09:00-10:00 dengan jumlah 29 kendaraan. Dibandingkan dengan hari Minggu, nilai akumulasi maksimum hari Senin lebih besar, hal ini dikarenakan lebih banyak pengujung yang menggunakan mobil dan para pekerja distributor barang yang memarkirkan kendaraan nya untuk keperluan bongkar atau muat barang di Pasar Baros. 
Tabel 2. Rekapitulasi Akumulasi Parkir Mobil

\begin{tabular}{ccccc}
\hline \multicolumn{5}{c}{ Hari Minggu } \\
\hline Interval & $\begin{array}{c}\text { Jumlah } \\
\text { Kendaraan } \\
\text { Masuk }\end{array}$ & Keluar & Akumulasi & $\begin{array}{c}\text { Kend. yang } \\
\text { sudah ada }\end{array}$ \\
\hline 06:00 - 07:00 & 10 & 5 & 9 & 4 \\
07:00 - 08:00 & 5 & 8 & 6 & \\
08:00 - 09:00 & $\mathbf{1 0}$ & 4 & 12 & \\
09:00 - 10:00 & 8 & 7 & 13 & \\
10:00 - 11:00 & 8 & 5 & $\mathbf{1 6}$ & \\
11:00 - 12:00 & 6 & 6 & $\mathbf{1 6}$ & \\
12:00 - 13:00 & 5 & $\mathbf{1 2}$ & 9 \\
13:00 - 14:00 & 6 & 5 & 10 \\
14:00 - 15:00 & 5 & 4 & 11 \\
15:00 - 16:00 & 5 & 6 & 10 \\
16:00 - 17:00 & 7 & 6 & 11 \\
17:00 - 18:00 & 2 & 7 & 6 \\
Jumlah & $\mathbf{7 7}$ & $\mathbf{7 5}$ & $\mathbf{1 2 9}$ \\
\hline
\end{tabular}

\begin{tabular}{ccccc}
\hline \multicolumn{5}{c}{ Hari Senin } \\
\hline Interval & $\begin{array}{c}\text { Jumlah } \\
\text { Kendaraan } \\
\text { Masuk }\end{array}$ & Keluar & Akumulasi & $\begin{array}{c}\text { Kend. yang } \\
\text { sudah ada }\end{array}$ \\
\hline 06:00 - 07:00 & 10 & 3 & 13 & 6 \\
07:00 - 08:00 & $\mathbf{1 2}$ & 5 & 20 & \\
08:00 - 09:00 & 7 & 4 & 23 & \\
09:00 - 10:00 & $\mathbf{1 2}$ & 6 & $\mathbf{2 9}$ & \\
10:00 - 11:00 & 5 & 10 & 24 & \\
11:00 - 12:00 & 5 & $\mathbf{1 2}$ & 17 & \\
12:00 - 13:00 & 4 & 10 & 11 & \\
13:00 - 14:00 & 8 & 8 & 11 & \\
14:00 - 15:00 & 8 & 8 & 11 & \\
15:00 - 16:00 & 6 & 5 & 12 \\
16:00 - 17:00 & 2 & 3 & 11 & \\
17:00 - 18:00 & 2 & 5 & 8 \\
Jumlah & $\mathbf{8 1}$ & $\mathbf{7 9}$ & $\mathbf{1 9 0}$ \\
\hline
\end{tabular}
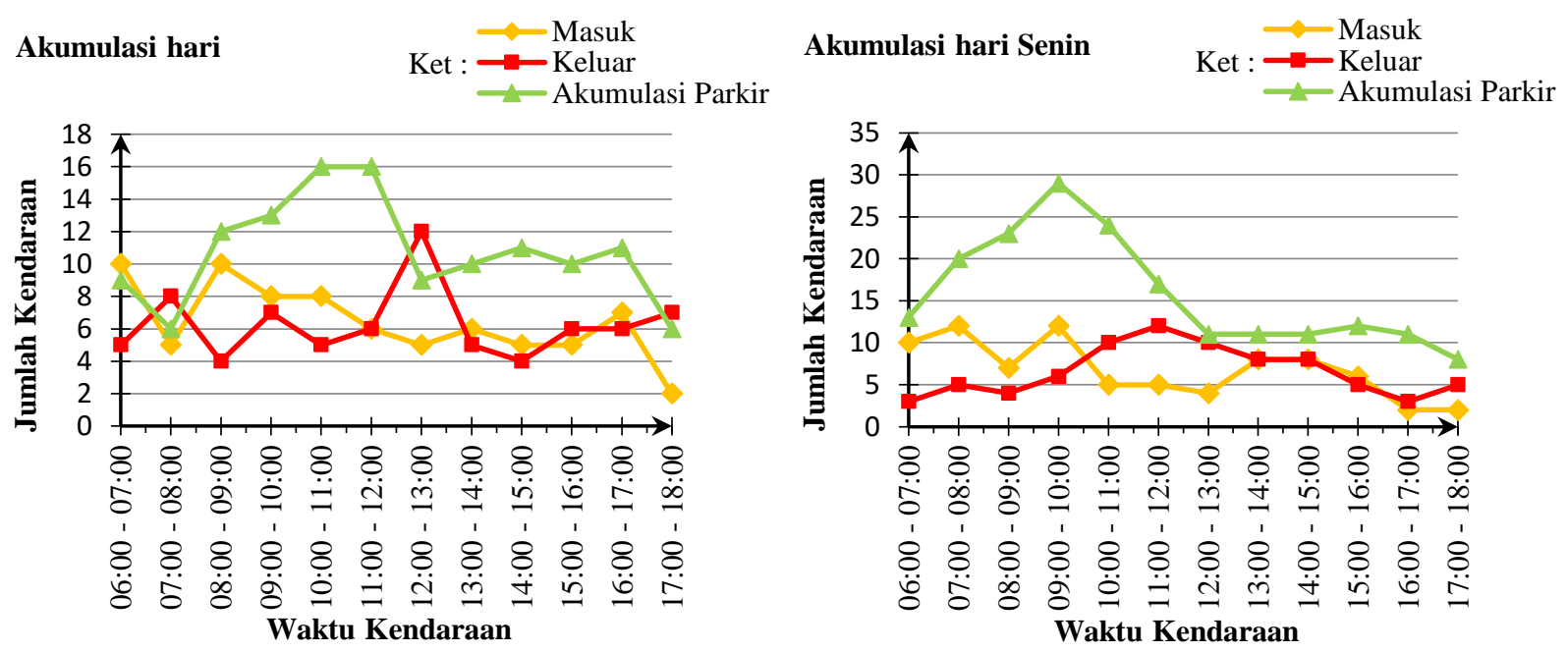

\subsection{Volume Parkir}

Berdasarkan Tabel 3 dibawah, jumlah sepeda motor yang masuk pada hari Minggu adalah 544, dan yang keluar 507 kendaraan. Terjadi selisih kendaraan yang masuk dan kendaraan yang keluar sebanyak 37 kendaraan. Sedangkan pada hari Senin jumlah kendaraan yang masuk yaitu 624, dan yang keluar 622 kendaraan. Terjadi selisih kendaraan yang masuk dan kendaraan yang keluar sebanyak 2 kendaraan. 
Tabel 3. Rekapitulasi Volume Parkir Sepeda Motor

\begin{tabular}{cccc}
\hline Hari Minggu & \multicolumn{3}{c}{} \\
\hline Interval & \multicolumn{2}{c}{ Jumlah } & Kendaraan \\
& Masuk & Keluar & yang \\
sudah ada & 31 \\
\hline 06:00 - 07:00 & 48 & 27 & \\
07:00 - 08:00 & $\mathbf{7 4}$ & 51 & \\
08:00 - 09:00 & 71 & $\mathbf{7 6}$ & \\
09:00 - 10:00 & 68 & 69 & \\
10:00 - 11:00 & 63 & 72 \\
11:00 - 12:00 & 41 & 33 \\
12:00 - 13:00 & 31 & 45 \\
13:00 - 14:00 & 43 & 50 \\
14:00 - 15:00 & 31 & 33 \\
15:00 - 16:00 & 25 & 26 \\
16:00 - 17:00 & 10 & 17 \\
17:00 - 18:00 & 8 & 8 \\
Jumlah & $\mathbf{5 4 4}$ & $\mathbf{5 0 7}$ \\
\hline
\end{tabular}

\begin{tabular}{|c|c|c|c|}
\hline \multicolumn{4}{|l|}{ Hari Senin } \\
\hline \multirow{2}{*}{ Interval } & \multicolumn{2}{|c|}{$\begin{array}{c}\text { Jumlah } \\
\text { Kendaraan }\end{array}$} & \multirow{2}{*}{$\begin{array}{c}\text { Kend. yang } \\
\text { sudah ada } \\
23\end{array}$} \\
\hline & Masuk & Keluar & \\
\hline $06: 00-07: 00$ & 97 & 58 & \\
\hline 07:00 - 08:00 & 62 & 61 & \\
\hline 08:00 - 09:00 & 85 & 65 & \\
\hline 09:00 - 10:00 & 78 & 86 & \\
\hline $10: 00-11: 00$ & 69 & 78 & \\
\hline $11: 00-12: 00$ & 57 & 91 & \\
\hline $12: 00-13: 00$ & 32 & 16 & \\
\hline $13: 00-14: 00$ & 45 & 53 & \\
\hline $14: 00-15: 00$ & 32 & 29 & \\
\hline $15: 00-16: 00$ & 27 & 39 & \\
\hline $16: 00-17: 00$ & 11 & 38 & \\
\hline $17: 00-18: 00$ & 6 & 8 & \\
\hline Jumlah & 624 & 622 & \\
\hline
\end{tabular}

Jumlah mobil yang masuk pada hari Minggu adalah 81 kendaraan, dan jumlah mobil yang keluar sebanyak 75 kendaraan. Sedangkan pada hari Senin jumlah mobil yang masuk yaitu 87 kendaraan, dan yang keluar sebanyak 79 kendaraan, dapat dilihat pada Tabel 4. Hasil pengamatan pada penelitian ini menunjukkan bahwa volume terbesar didapat adalah untuk sepeda motor yang terjadi pada hari Senin yaitu 624 kendaraan.

Tabel 4. Rekapitulasi Volume Parkir Mobil

\begin{tabular}{cccc}
\hline & Hari Minggu & \\
\hline Interval & \multicolumn{2}{c}{ Jumlah } \\
Kendaraan & $\begin{array}{c}\text { Kend. yang } \\
\text { sudah ada } \\
\text { Masuk }\end{array}$ & Keluar & 4 \\
\hline 06:00 - 07:00 & 10 & 5 & \\
07:00 - 08:00 & 5 & 8 & \\
08:00 - 09:00 & $\mathbf{1 0}$ & 4 & \\
09:00 - 10:00 & 8 & 7 & \\
10:00 - 11:00 & 8 & 5 &
\end{tabular}

\begin{tabular}{cccc}
\hline \multicolumn{4}{c}{ Hari Senin } \\
\hline Interval & \multicolumn{2}{c}{$\begin{array}{c}\text { Jumlah } \\
\text { Kendaraan } \\
\text { Masuk }\end{array}$} & $\begin{array}{c}\text { Kend. yang } \\
\text { sudah ada }\end{array}$ \\
\hline 06:00 - 07:00 & 10 & 3 & 6 \\
07:00- 08:00 & $\mathbf{1 2}$ & 5 & \\
08:00- 09:00 & 7 & 4 & \\
09:00- 10:00 & $\mathbf{1 2}$ & 6 & \\
10:00- 11:00 & 5 & 10 & \\
& & & \\
\end{tabular}

Tabel 4. Lanjutan

\begin{tabular}{cccc}
\hline \multicolumn{4}{c}{ Hari Minggu } \\
\hline Interval & $\begin{array}{c}\text { Jumlah } \\
\text { Kendaraan } \\
\text { Masuk }\end{array}$ & $\begin{array}{c}\text { Kend. yang } \\
\text { Sudah ada }\end{array}$ & 4 \\
\hline 11:00 - 12:00 & 6 & 6 & \\
12:00 - 13:00 & 5 & $\mathbf{1 2}$ & \\
13:00 - 14:00 & 6 & 5 & \\
14:00 - 15:00 & 5 & 4 & \\
15:00 - 16:00 & 5 & 6 & \\
16:00 - 17:00 & 7 & 6 & \\
17:00 - 18:00 & 2 & 7 & \\
Jumlah & $\mathbf{8 1}$ & $\mathbf{7 5}$ & \\
\hline
\end{tabular}

\begin{tabular}{|c|c|c|c|}
\hline \multicolumn{4}{|c|}{ Hari Senin } \\
\hline \multirow{2}{*}{ Interval } & \multicolumn{2}{|c|}{$\begin{array}{c}\text { Jumlah } \\
\text { Kendaraan }\end{array}$} & \multirow{2}{*}{$\begin{array}{c}\text { Kend. yang } \\
\text { sudah ada } \\
6 \\
\end{array}$} \\
\hline & Masuk & Keluar & \\
\hline $11: 00-12: 00$ & 5 & 12 & \\
\hline $12: 00-13: 00$ & 4 & 10 & \\
\hline $13: 00-14: 00$ & 8 & 8 & \\
\hline $14: 00-15: 00$ & 8 & 8 & \\
\hline $15: 00-16: 00$ & 6 & 5 & \\
\hline $16: 00-17: 00$ & 2 & 3 & \\
\hline $17: 00-18: 00$ & 2 & 5 & \\
\hline Jumlah & 87 & 79 & \\
\hline
\end{tabular}




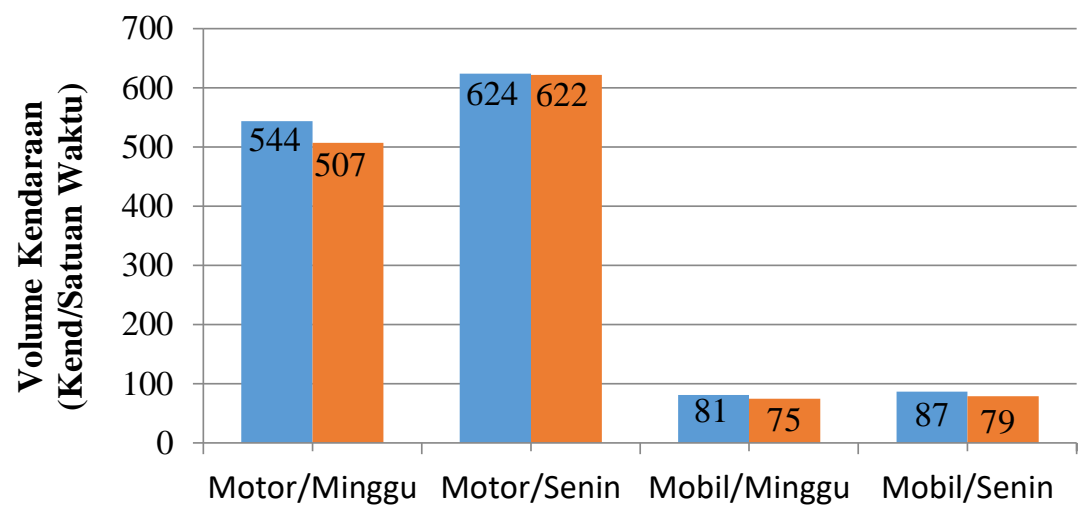

Jenis Kendaraan/Hari

Keterangan : $\quad$ Masuk

Keluar

\subsection{Durasi Parkir}

Durasi parkir rata-rata dari masing-masing hari dan jenis kendaraan dapat dilihat pada Tabel 5 dan dari tabel tersebut menunjukkan bahwa durasi rata-rata maksimum untuk sepeda motor terjadi pada hari Senin sebesar 1,26 atau 2 jam 6 menit. Durasi rata-rata terbesar untuk mobil terjadi pada hari Minggu sebesar 1,67 atau 2 jam 47 menit.

Tabel 5. Rekapitulasi Durasi Parkir Rata-Rata

\begin{tabular}{clcc}
\hline No. & \multicolumn{1}{c}{ Hari/Tanggal } & $\begin{array}{c}\text { Jenis } \\
\text { Kendaraan }\end{array}$ & $\begin{array}{c}\text { Durasi Rata-rata } \\
\text { (jam/kend) }\end{array}$ \\
\hline 1 & Minggu/29 Maret 2020 & Motor & 0,80 \\
2 & Senin/30 Maret 2020 & Motor & 1,26 \\
3 & Minggu/29 Maret 2020 & Mobil & 1,67 \\
4 & Senin/30 Maret 2020 & Mobil & 1,39 \\
\hline
\end{tabular}

\subsection{Kapastitas Parkir}

Berdasarkan Tabel 6 dapat diketahui kapasitas parkir untuk sepeda motor terbesar terjadi pada hari Minggu sebesar $121 \mathrm{SRP/Jam/Kendaraan.} \mathrm{Kapasitas} \mathrm{terbesar} \mathrm{untuk} \mathrm{mobil} \mathrm{terjadi} \mathrm{pada} \mathrm{hari} \mathrm{Senin} \mathrm{sebesar} 15$ $\mathrm{SRP} / \mathrm{Jam} /$ Kendaraan. Dengan durasi rata-rata yang lebih kecil maka kapasitas parkirnya akan semakin besar.

Tabel 6. Rekapitulasi Kapasitas Parkir

\begin{tabular}{cccccc}
\hline No & Hari/Tanggal & $\begin{array}{c}\text { Jenis } \\
\text { Kendaraan }\end{array}$ & $\begin{array}{c}\text { Jumlah Petak } \\
\text { Parkir (SRP) }\end{array}$ & $\begin{array}{c}\text { Durasi Rata-Rata } \\
\text { (Jam) }\end{array}$ & $\begin{array}{c}\text { Kapasitas Parkir } \\
\text { (SRP/Jam/Kendaraan) }\end{array}$ \\
\hline & $\begin{array}{c}\text { Minggu, } \\
29 \text { Maret 2020 }\end{array}$ & Motor & 97 & 0,80 & 120,9 \\
2 & $\begin{array}{c}\text { Senin, } \\
20 \text { Maret 2020 } \\
\text { Minggu, }\end{array}$ & Motor & 97 & 1,26 & 76,96 \\
3 & Mobil & 20 & 1,67 & 11,96 \\
4 & $\begin{array}{c}\text { Maret 2020 } \\
\text { Senin, }\end{array}$ & Mobil & 20 & 1,39 & 14,44 \\
\hline
\end{tabular}

\subsection{Indeks Parkir}

Setelah melalui tahap perhitungan dapat dilihat pada Tabel 7, indeks parkir sepeda motor yang terjadi berkisar antara 63,69 \% - 123,44 \% (didasarkan pada akumulasi parkir maksimum kendaraan per 15 menit). Dari nilai indeks parkir yang didapat, ternyata area parkir existing di Pasar Baros tidak dapat memenuhi kebutuhan parkir pada saat kondisi parkir mencapai akumulasi maksimum. Sedangkan indeks parkir mobil yang terjadi berkisar antara $133,83 \%-200,83 \%$, dengan nilai indeks parkir yang melebihi angka $100 \%$ maka area parkir existing 
mobil di Pasar Baros tidak dapat memenuhi kebutuhan parkir pada saat kondisi parkir mencapai akumulasi maksimum.

Tabel 7. Rekapitulasi Indeks Parkir

\begin{tabular}{|c|c|c|c|c|}
\hline \multicolumn{2}{|c|}{ Jenis Kendaraan } & \multicolumn{3}{|l|}{ Motor } \\
\hline No & Hari/Tanggal & $\begin{array}{c}\text { Akumulasi Parkir } \\
\text { (kendaraan/ } \\
15 \text { menit) }\end{array}$ & $\begin{array}{c}\text { Kapasitas Parkir } \\
\text { (SRP/Jam/Kendaraan) }\end{array}$ & $\begin{array}{c}\text { Indeks Parkir } \\
(\%)\end{array}$ \\
\hline 1 & $\begin{array}{c}\text { Minggu, } \\
29 \text { Maret } 2020\end{array}$ & 77 & 120,9 & 63,69 \\
\hline 2 & $\begin{array}{c}\text { Senin, } \\
30 \text { Maret } 2020\end{array}$ & 95 & 76,96 & 123,44 \\
\hline \multicolumn{2}{|c|}{ Jenis Kendaraan } & Mobil & & \\
\hline No & Hari/Tanggal & $\begin{array}{c}\text { Akumulasi Parkir } \\
\text { (kendaraan/ } \\
15 \text { menit) }\end{array}$ & $\begin{array}{c}\text { Kapasitas Parkir } \\
\text { (SRP/Jam/Kendaraan) }\end{array}$ & $\begin{array}{c}\text { Indeks Parkir } \\
(\%)\end{array}$ \\
\hline 1 & $\begin{array}{c}\text { Minggu, } \\
29 \text { Maret } 2020\end{array}$ & 16 & 11,96 & 133,83 \\
\hline 2 & $\begin{array}{c}\text { Senin, } \\
\text { 30 Maret } 2020\end{array}$ & 29 & 14,44 & 200,83 \\
\hline
\end{tabular}

\subsection{Tingkat Pergantian Parkir (Turnover)}

Tabel 8 dibawah menjelaskan tentang rekapitulasi tingkat pergantian parkir (turnover) pada tiap-tiap hari dan jenis kendaraan. Dapat dilihat pada Tabel 8 bahwa tingkat pergantian parkir (turnover) untuk sepeda motor terbesar terjadi pada hari Senin sebesar 7 kendaraan/SRP/jam dari volume parkir 624 kendaraan. Untuk tingkat pergantian parkir (turnover) mobil terbesar dengan jumlah 5 kendaraan/SRP/jam dari volume parkir 87 kendaraan terjadi pada hari Senin.

Tabel 8. Rekapitulasi Tingkat Pergantian Parkir (Turnover)

\begin{tabular}{|c|c|c|c|c|}
\hline \multicolumn{2}{|c|}{ Jenis Kendaraan } & \multicolumn{3}{|l|}{ Motor } \\
\hline No & Hari/Tanggal & $\begin{array}{l}\text { Volume Parkir } \\
\text { (kendaraan) }\end{array}$ & $\begin{array}{c}\text { Jumlah Petak Tersedia } \\
\text { (SRP) }\end{array}$ & $\begin{array}{c}\text { Turnover } \\
\text { (Kendaraan) }\end{array}$ \\
\hline 1 & $\begin{array}{c}\text { Minggu, } \\
29 \text { Maret } 2020\end{array}$ & 455 & 97 & $5,61 \sim 6$ \\
\hline 2 & $\begin{array}{c}\text { Senin, } \\
30 \text { Maret } 2020\end{array}$ & 624 & 97 & $6,43 \sim 7$ \\
\hline \multicolumn{2}{|c|}{ Jenis Kendaraan } & Mobil & & \\
\hline No & Hari/Tanggal & $\begin{array}{l}\text { Volume Parkir } \\
\text { (kendaraan) }\end{array}$ & $\begin{array}{c}\text { Jumlah Petak Tersedia } \\
\text { (SRP) }\end{array}$ & $\begin{array}{c}\text { Turnover } \\
\text { (Kendaraan) }\end{array}$ \\
\hline 1 & $\begin{array}{c}\text { Minggu, } \\
29 \text { Maret } 2020\end{array}$ & 81 & 20 & $4,05 \sim 4$ \\
\hline 2 & $\begin{array}{c}\text { Senin, } \\
30 \text { Maret } 2020\end{array}$ & 87 & 20 & $4,35 \sim 5$ \\
\hline
\end{tabular}

\subsection{Analisis Kebutuhan Parkir}

Kebutuhan parkir adalah kebutuhan ruang parkir yang berdasarkan perbandingan permintaan (saat akumulasi puncak) terhadap penawaran (demand) adalah besarnya kebutuhan parkir yang harus dipenuhi oleh suatu area parkir. Jumlah ruang parkir yang dibutuhkan dapat dihitung dengan beberapa cara, antara lain dengan rumus dasar analisis parkir menurut Pignataro, L.J (1973).

Contoh perhitungan:

$\mathrm{Z}=\frac{544 \times 0,80}{12}=\mathbf{3 6 , 2 7} \sim \mathbf{3 7} \mathrm{SRP}$

Dimana (Z) adalah Kebutuhan ruang parkir. 
Dari hasil perhitungan dengan menggunakan rumus Pignataro, L.J (1973), maka selanjutnya direkapitulasi sesuai dengan jenis kendaraan dan masing-masing hari survey. Tabel 9 menunjukkan bahwa kebutuhan ruang parkir paling banyak untuk sepeda motor terjadi pada hari Senin sebesar 66 SRP. Sedangkan untuk mobil kebutuhan ruang parkir paling banyak terjadi pada hari Minggu dengan kebutuhan sebesar 12 SRP. Dapat disimpulkan bahwa area parkir existing di Pasar Baros untuk sepeda motor membutuhkan ruang parkir sebanyak 66 SRP, dan area parkir existing mobil saat ini membutuhkan 12 SRP.

Tabel 9. Rekapitulasi Kebutuhan Ruang Parkir

\begin{tabular}{ccccccc}
\hline No & \multicolumn{1}{c}{$\begin{array}{c}\text { Hari/ } \\
\text { Tanggal }\end{array}$} & $\begin{array}{c}\text { Jenis } \\
\text { Kendaraan }\end{array}$ & $\begin{array}{c}\text { Lama } \\
\text { Survei } \\
\text { (Jam) }\end{array}$ & $\begin{array}{c}\text { Volume Parkir } \\
\text { (Kendaraan) }\end{array}$ & $\begin{array}{c}\text { Durasi Rata-Rata } \\
\text { (Jam) }\end{array}$ & $\begin{array}{c}\text { Kebutuhan Ruang } \\
\text { Parkir (SRP) }\end{array}$ \\
\hline 1 & $\begin{array}{l}\text { Minggu/ } \\
29 \text { Maret 2020 }\end{array}$ & Motor & 12 & 544 & 0,80 & 36,27 \\
2 & $\begin{array}{l}\text { Senin/ } \\
30 \text { Maret 2020 }\end{array}$ & Motor & 12 & 624 & 1,26 & 65,52 \\
3 & $\begin{array}{l}\text { Minggu/ } \\
29 \text { Maret 2020 }\end{array}$ & Mobil & 12 & 81 & 1,67 & 11,27 \\
4 & $\begin{array}{l}\text { Senin/ } \\
30 \text { Maret 2020 }\end{array}$ & Mobil & 12 & 87 & 1,39 & 10,08 \\
\hline
\end{tabular}

\subsection{Pemecahan Masalah}

Berdasarkan hasil analisis karakteristik parkir dengan mengacu pada Pedoman Teknis Penyelenggaraan Fasilitas Parkir, Direktorat Jenderal Perhubungan Darat 1996 dan keadaan faktual di lapangan maka dapat disimpulkan bahwa ruang parkir untuk kondisi sekarang tidak dapat memenuhi kebutuhan parkir para pengujung pasar. Maka perlu adanya rekomendasi penambahan dan perencanaan ruang parkir.

\section{Penambahan Ruang Parkir Sepeda Motor}

Dari keadaan existing di lapangan, berdasarkan hasil perhitungan indeks parkir sepeda motor yang terjadi berkisar antara 63,69 \% - 123,44 \% (didasarkan pada akumulasi parkir maksimum kendaraan per 15 menit). Dari nilai indeks parkir yang didapat, ternyata area parkir motor di Pasar Baros tidak dapat memenuhi kebutuhan parkir dengan nilai indeks parkir yang melebihi angka 100\%. Penambahan luasan area parkir sebesar 257,4 $\mathrm{m}^{2}$ di area parkir existing, pemindahan tempat penampungan sampah yang kemudian lahannya dipakai untuk ruang parkir sepeda motor, pemindahan lapak-lapak pedagang kaki lima agar lahan yang tersedia memenuhi kebutuhan parkir yang ada. Berikut ini adalah gambaran rekomendasi penambahan ruang parkir untuk sepeda motor.

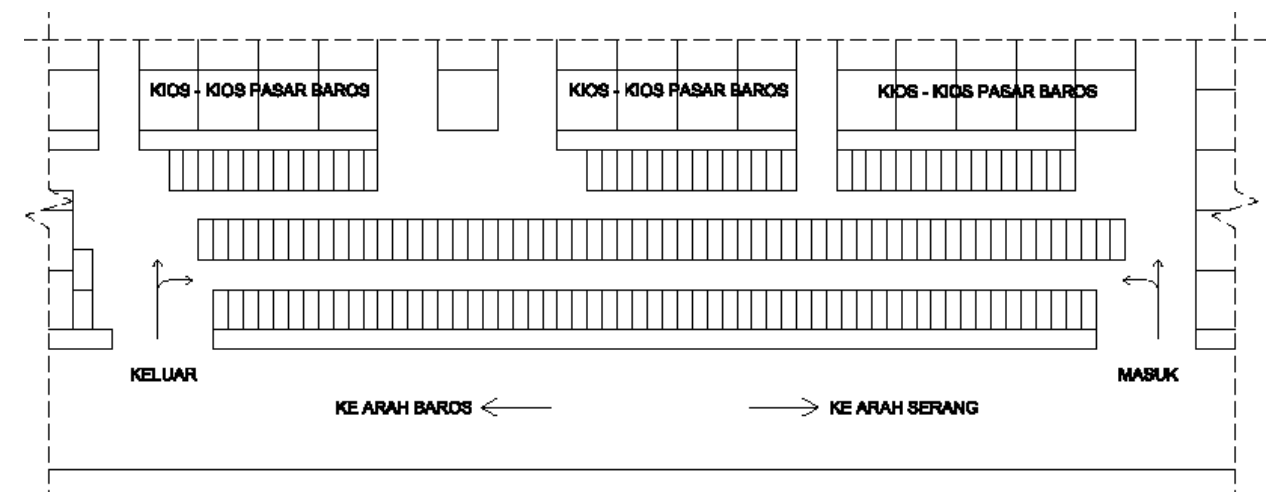

Gambar 1. Rekomendasi Penambahan Ruang Parkir Sepeda Motor

Berdasarkan Gambar 1 dapat dilihat bahwa area ruang parkir sepeda motor menjadi lebih luas karena tidak ada tempat penampungan sampah dan pedagang kaki lima di area parkir tersebut, terdapat 165 petak parkir sepeda motor. Rekomendasi untuk akses masuk dan keluar kendaraan dibuat terpisah dimana akses masuk terdapat pada bagian sebelah kanan dari depan pasar dan akses keluar di sebelah kiri untuk mempermudah para 
pengunjung dan mengurangi resiko antrian kendaraan dan kemacetan jika akses masuk dan keluar disatukan. Terdapat dua jalur gang yang masing-masing berukuran 1,5 meter untuk manuver sepeda motor yang hendak masuk atau keluar dari ruang parkir.

\section{Perencanaan Ruang Parkir Mobil}

Lahan parkir di Pasar Baros sekarang ini hanya bisa digunakan untuk kendaraan sepeda motor. Sehingga belum ada ruang parkir yang diperuntukan untuk kendaraan mobil. Dinas Pemerintah Provinsi Banten berencana untuk melakukan pengembangan lahan di Pasar Baros seluas 1,4 Hektar yang berada tepat di belakang pasar, dalam hal ini penulis merekomendasikan perencanaan ruang parkir untuk mobil di belakang pasar. Rekomendasi untuk ruang parkir mobil pada Pasar Baros membutuhkan lahan seluas 1102,5 $\mathrm{m}^{2}$ dan akses untuk masuk ke ruang parkir mobil dari samping pasar. Penulis juga merekomendasikan akses masuk dari belakang pasar dengan panjang 5 meter dan lebar 1,5 meter disesuaikan dengan keadaan dilapangan dimana tinggi permukaan lantai Pasar Baros ke ruang parkir mobil yaitu beda tinggi 1 meter, maka dibuatkan tangga dan tanjakan agar pengujung pasar yang menggunakan mobil dan yang akan bongkar muat barang bisa langsung masuk dari belakang pasar.

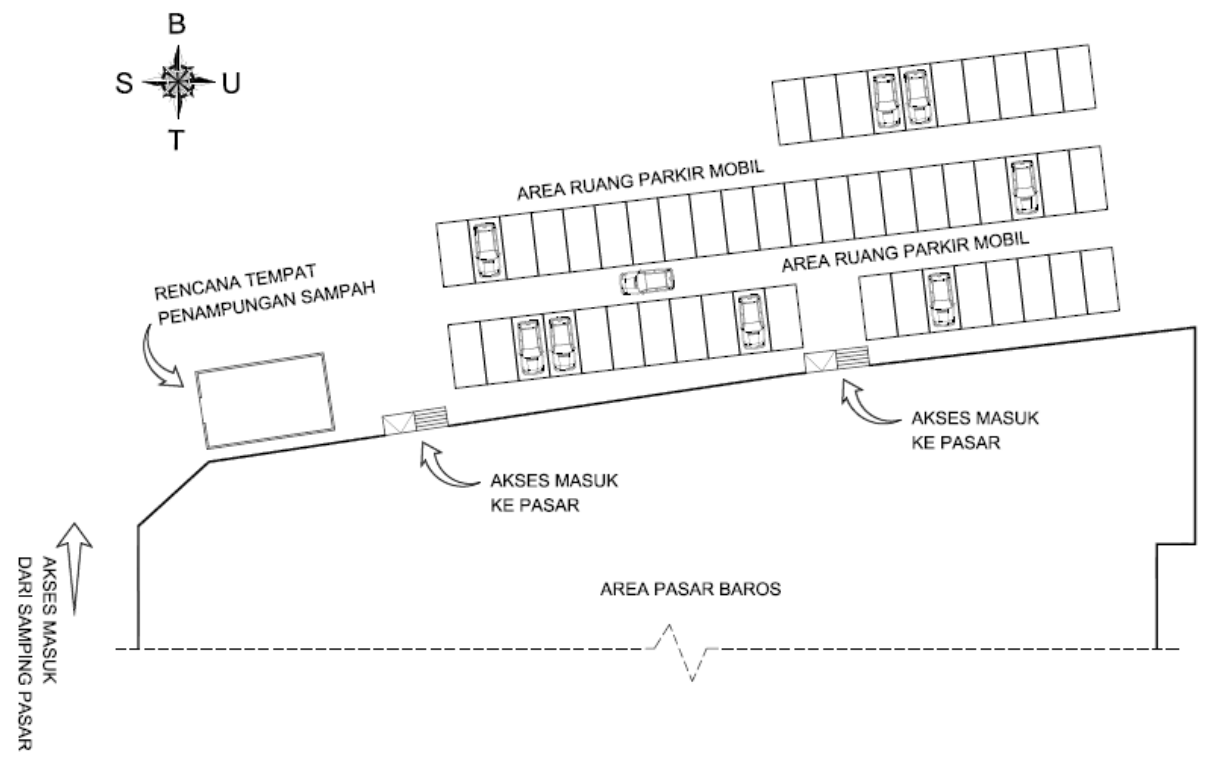

Gambar 2. Rekomendasi Perencanaan Ruang Parkir Mobil

Dapat dilihat pada Gambar 2 bahwa rekomendasi ruang parkir mobil berada di belakang pasar, dengan menggunakan pola parkir sudut $90^{\circ}$, terdapat 50 petak parkir dengan ukuran sesuai Satuan Ruang Parkir (SRP) mobil penumpang dari Pedoman Teknis Penyelenggaraan Fasilitas Parkir dan 2 jalur gang dengan lebar 3 meter. Selain perencanaan ruang parkir mobil, penulis juga akan menjelaskan tentang rencana pemindahan tempat penampungan sampah dimana pada kondisi faktual dilapangan area tempat penampungan sampah Pasar Baros berada di depan pasar, selain mengurangi kapasitas ruang parkir sepeda motor, tempat pembuangan sampah yang berada di depan pasar mengurangi estetika keindahan pasar. Maka dari itu perlu rekomendasi perencanaan tempat penampungan sampah. Berdasarkan Standar Nasional Indonesia (SNI) tentang 'Pengelolaan Sampah di Permukiman' klasifikasi luas lahan untuk pusat perdagangan $\pm 10-50 \mathrm{~m}^{2}$. Dengan luas $50 \mathrm{~m}^{2}$ atau panjang $10 \mathrm{~m}$ dan lebar $5 \mathrm{~m}$. Tinggi kira-kira tempat penampungan sampah adalah $2 \mathrm{~meter}$, di bagian depan TPS terdapat akses untuk membuang sampah atau mengangkut sampah, dan terdapat satu petak parkir khusus untuk mobil truk yang bertujuan untuk mengangkut sampah. Gambaran rekomendasi perencanaan tempat penampungan sampah pada Pasar Baros dapat dilihat pada Gambar 3. 


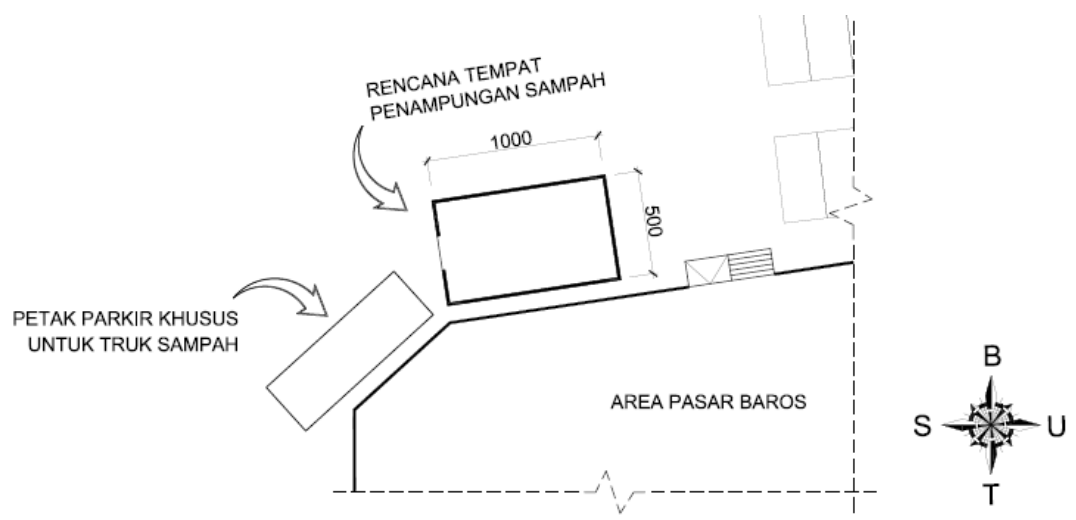

Gambar 3. Rekomendasi Perencanaan Tempat Penampungan Sampah

Diharapkan dengan pemindahan tempat penampungan sampah ke belakang pasar dapat menambah kapasitas pada ruang parkir existing Pasar Baros, dan estetika pasar menjadi lebih indah. Dengan ukuran yang lebih luas diharapkan dapat menampung lebih banyak sampah supaya tidak berantakan dan tidak menganggu aktifitas perparkiran di sekitar pasar.

\section{KESIMPULAN}

Kesimpulan yang didapat berdasarkan pengumpulan data, hasil analisis karakteristik parkir dan keadaan faktual di area ruang parkir Pasar Baros yaitu:

1. Kondisi existing ruang parkir di Pasar Baros saat ini yaitu luas area parkir kurang lebih $540 \mathrm{~m} 2$ dan terdapat 97 jumlah petak parkir sepeda motor. Luas ruang parkir tersebut digunakan untuk parkir sepeda motor saja, sedangkan untuk mobil hanya bisa parkir diluar pasar yaitu di samping Pasar Baros, terdapat lahan kosong milik perorangan yang di manfaatkan untuk parkir kendaraan roda 4 (mobil) yang kira-kira terdapat 20 petak parkir untuk mobil.

2. Dari nilai Indeks parkir sepeda motor yang terjadi berkisar antara $63,69 \%-123,44 \%$ tidak mampu memenuhi kebutuhan parkir dengan nilai Indeks parkir yang melebihi angka $100 \%$. Sedangkan nilai Indeks parkir mobil juga tidak mampu memenuhi kebutuhan parkir dengan nilai yang terjadi berkisar antara 133,83 $\%-200,83 \%$. Berdasarkan analisis kebutuhan ruang parkir, dapat disimpulkan bahwa area parkir existing di Pasar Baros untuk sepeda motor membutuhkan ruang parkir sebanyak 66 SRP, dan area parkir existing mobil saat ini hanya membutuhkan 12 SRP.

3. Rekomendasi ruang parkir yang efektif pada Pasar Baros yaitu:

a. Penambahan luasan area parkir untuk sepeda motor dengan panjang 28,6 m dan lebar $9 \mathrm{~m}$ atau luas $257,4 \mathrm{~m}^{2}$, dengan mengacu pada standar pemakaian dan kebutuhan ruang parkir, maka yang cocok untuk desain parkir di Pasar Baros adalah dengan parkir pulau dengan sudut $90^{\circ}$.

b. Perencanaan ruang parkir mobil dengan luas $1102,5 \mathrm{~m}^{2}$ atau dengan ukuran panjang 52,5 meter dan lebar 21 meter, diletakkan di belakang pasar dengan desain pola parkir pulau sudut $90^{\circ}$.

c. Pemindahan tempat penampungan sampah ke belakang pasar agar menambah luas lahan ruang parkir yang kemudian lahannya bisa dipakai untuk ruang parkir sepeda motor, dan menambah estetika keindahan pasar.

\section{DAFTAR PUSTAKA}

Abdul Aziz, B.R. 2011. Analisis Kapasitas Ruang Parkir Mobil Untuk Kawasan FMIPA, FBS Dan Rektorat Universitas Negeri Semarang. Jurnal. Semarang, Indonesia.

Abubakar, Iskandar, dkk. 1998. Pedoman Perencanaan dan Pengoperasian Fasilitas Parkir. Jakarta: Direktorat Bina Sistem Lalu Lintas dan Angkutan Kota Dirjen Perhubungan Darat.

Anonim. 1996. Pedoman Teknis Penyelenggaraan Fasilitas Parkir Direktorat Jendral Perhubungan Darat. Jakarta.

Hobbs, F.D. 1995. Traffic and Engineering, Second Edition. Terjemahan oleh Suprapto TM dan Waldjono. Penerbit Gajah Mada Press. Yogyakarta. 
Keputusan Menteri Perhubungan Nomor : KM 66 Tahun 1993 tentang Fasilitas Parkir Untuk Umum dan Keputusan Menteri Perhubungan Nomor: KM 4 Tahun 1994 Tentang Tata Cara Parkir Kendaraan Bermotor.

Pradana, M. F. 2012. Analisa Karakteristik Parkir Pada Fakultas Teknik Universitas Sultan Ageng Tirtayasa. Serang. Indonesia.

Rachman, F. 2011. Analisis Kapasitas Ruang Parkir Sepeda Motor Kawasan FIP, FIS, FE, Dan FH Universitas Negeri Semarang. Jurnal. Semarang, Indonesia.

Rosdiyani, T. 2016. Kajian Kebutuhan Ruang Parkir Sebagai Pengendali Lalu Lintas di Kampus Universitas Muhammadiyah Surakarta, Jurnal. Surakarta, Indonesia.

Syarifuddin, F. 2017. Kebutuhan Ruang Parkir Pada Rumah Sakit Bhayangkara Di Kota Makassar. Jurnal. Makassar, Indonesia.

Undang-Undang RI No. 22 Tahun 2009 Tentang Lalu Lintas dan Angkutan Jalan. 